\title{
Clinical Analysis and Risk Factors in Laryngeal Leukoplasia
}

\author{
Fatih Tetik' (1), Meltem Esen Akpınar² (D), Eymen Oruç3 (D), Irmak Uçak ${ }^{4}$ (D), Berna Uslu Coşkun² (1)
}

1Department of Otorhinolaryngology, University of Health Sciences Gaziosmanpaşa Taksim Training and Research Hospital, i̇stanbul, Turkey 2Department of Otorhinolaryngology, University of Health Sciences İstanbul Şişli Hamidiye Etfal Training and Research Hospital, i̇stanbul, Turkey ${ }^{3}$ Clinic of Otorhinolaryngology, İstanbul Çatalca ilyas Çokay State Hospital, İstanbul, Turkey

${ }^{4}$ Department of Otorhinolaryngology, University of Health Sciences İstanbul Sultan Abdulhamid Han Training and Research Hospital, İstanbul, Turkey

Cite this article as: Tetik F, Esen Akpınar M, Oruç E, Uçak I, Uslu Coşkun B. Clinical Analysis and Risk Factors in Laryngeal Leukoplasia. JAREM 2018; 8(3): 198-202.

\begin{abstract}
Objective: Leukoplasia requires careful clinical follow-up with recurrent biopsies, regardless of the histopathological grade of dysplasia, because it has a potential risk of malignant transformation. This study aimed to investigate the clinical features and risk factors of laryngeal leukoplasia.

Methods: Overall, 174 lesions of 97 patients who were diagnosed with vocal fold dysplasia between 2007 and 2013 at our clinic were retrospectively analyzed. Histopathological classification of laryngeal leukoplakia, gender, age, systemic diseases, smoking habits, initial symptoms, duration of symptoms, location, size and number of lesions, and recurrence of the lesion were recorded.

Results: Ten (10.30\%) of the patients were females and 87 (89.70\%) were males. The average age was 56.95 years. The initial sypmtom of all patients was hoarseness. Average cigarette use was 38.82 packets/year; smoking frequency was $93.8 \%$; and reflux frequency was $16.6 \%$. Indirect and direct laryngoscopic examinations revealed that 103 (59.53\%) patients had leukoplasia and 70 (40.46\%) patients had vocal cord irregularities. Mild dysplasia was the most common histopathological diagnosis. The lesion location was $45.1 \%$ in the anterior $1 / 3,32.34 \%$ in the middle $1 / 3$, and $22.55 \%$ in the posterior $1 / 3$ of the vocal cord. The age distribution, sex ratio, duration of initial symptom, reflux rate, smoking rate, and localization were not statistically significant $(p>0.05)$ in patients with and without recurrence. Leukoplasia recurrence rate was significantly higher $(p<0.05)$ than irregularity rate.

Conclusion: In laryngeal leukoplasia, biopsy and histopathological examination are important for evaluating epithelial dysplasia and its degree. Histopathologically, factors such as presence and severity of dysplasia and smoking increase the risk of developing malignancy. Clinically homogeneous leukoplasia has a higher recurrence rate than nonhomogeneous irregularity. However, age distribution, sex, duration of initial symptom, reflux rate, smoking, and localization does not increase the recurrence rate, according to the results of this study.
\end{abstract}

Keywords: Leukoplasia, dysplasia, vocal cord, larynx

ORCID IDs of the authors: F.T. 0000-0001-07468-6111; M.E.A. 0000-0001-5281-1903; E.O. 0000-0001-7153-5721; I.U. 0000-0002-2177-0552; B.U.C. 00000001-3854-2760

\section{INTRODUCTION}

Leukoplakia is a clinical term describing white lesions in mucous membranes. Dysplasia is a pathological term showing cellular atypia and structural changes in the epithelium. Laryngeal leukoplakia is considered to be precancerous because of the possibility of transformation into squamous cell carcinoma (SCC). Smoking, alcohol, gastric reflux, viral infections, poor use of sound, and toxic gas inhalation are the main risk factors for leukoplakia.

Diagnosis is made by direct laryngoscopy. A white plaque that is not easily removed from the underlying mucosa is specific for diagnosis (1). A biopsy is performed to determine the presence of dysplasia during laryngoscopy. The most important param- eter in pathological examination is the presence of dysplasia and its severity.

The coexistence of leukoplakia with irregularities increases the suspicion of carcinoma in preoperative evaluation. In such a case, there is a debate about the intervention that should be done during the operation. An excisional biopsy, stripping, and laser ablation may be the options for the surgical treatment.

With regard to histopathology, a careful clinical follow-up with recurrent biopsies is required regardless of the degree of dysplasia.

In this study, the risk factors that may help in making decisions about the surgical intervention in the preoperative examination in patients with vocal cord leukoplakia are evaluated. 


\section{METHODS}

Approval for the study was obtained from the Clinical Research Ethics Committee of Şişli Hamidiye Etfal Training and Research Hospital (22/10/2013-505). The files of the patients who underwent direct laryngoscopy between 2007 and 2013 were retrospectively reviewed. Patients with vocal cord leukoplakia were included in the study. Patients with an ulcerovegetan mass, polyps, nodules, and previously diagnosed laryngeal carcinoma were excluded from the study.

Gender, age, smoking, symptoms and symptom duration, examination findings, localization of the lesion, histopathological classification of leukoplakia, and recurrence were analyzed.

In regard to histopathology, the lesions were divided into four groups $(2,3)$ :

Group I: Inflammatory changes, hyperkeratosis

Group II: Mild-to-moderate dysplasia

Group III: Severe dysplasia and carcinoma in situ (CIS)

Group IV: Micro invasive and invasive SCC

The presence of irregularities associated with leukoplakia and the location of the lesion were evaluated. The location of the lesion was evaluated in six groups according to the cord and level (Figure 1).

\section{Statistical Analysis}

Data were analyzed using the Statistical Package for the Social Sciences version 21.0 program (IBM Corp., Armonk, NY, USA). Data were expressed as the mean \pm standard deviation, minimum-maximum, ratio, and frequency in descriptive statistics. The Kolmogorov-Smirnov test was used for control of the distribution of the variables. An independent samples t-test and the Mann-Whitney $U$ test were used for a quantitative data analysis; Chi-squared test was used for the analysis of qualitative data.

\section{RESULTS}

Ten (10.30\%) of the patients were female and $87(89.70 \%)$ were male. The mean age was 56.95. All patients presented with symptoms of hoarseness. The mean smoking rate was 38.82 packs/year, and the rate of smoking was $93.8 \%$. The incidence of reflux was $16.6 \%$.

In indirect and direct laryngoscopic examinations, 103 (59.53\%) patients had leukoplakia, and $70(40.46 \%)$ patients had vocal cord irregularities. The number of non-smokers was 6 (6.18\%); 5 (83.33\%) of these patients had mild dysplasia, and 1 (16.67\%) had severe dysplasia. Mild dysplasia was the most common histopathological diagnosis. The distribution of histopathological examination results was found to be $8.67 \%$ in Group I, 52.02\% in Group II, 30.06\% in Group III, and $9.25 \%$ in Group IV (Table 1). The most common location of the lesions was the anterior onethird of the vocal cords, and posterior involvement was rare.

The age distribution, gender ratio, first symptom duration, reflux rate, smoking rate, and localization were not statistically

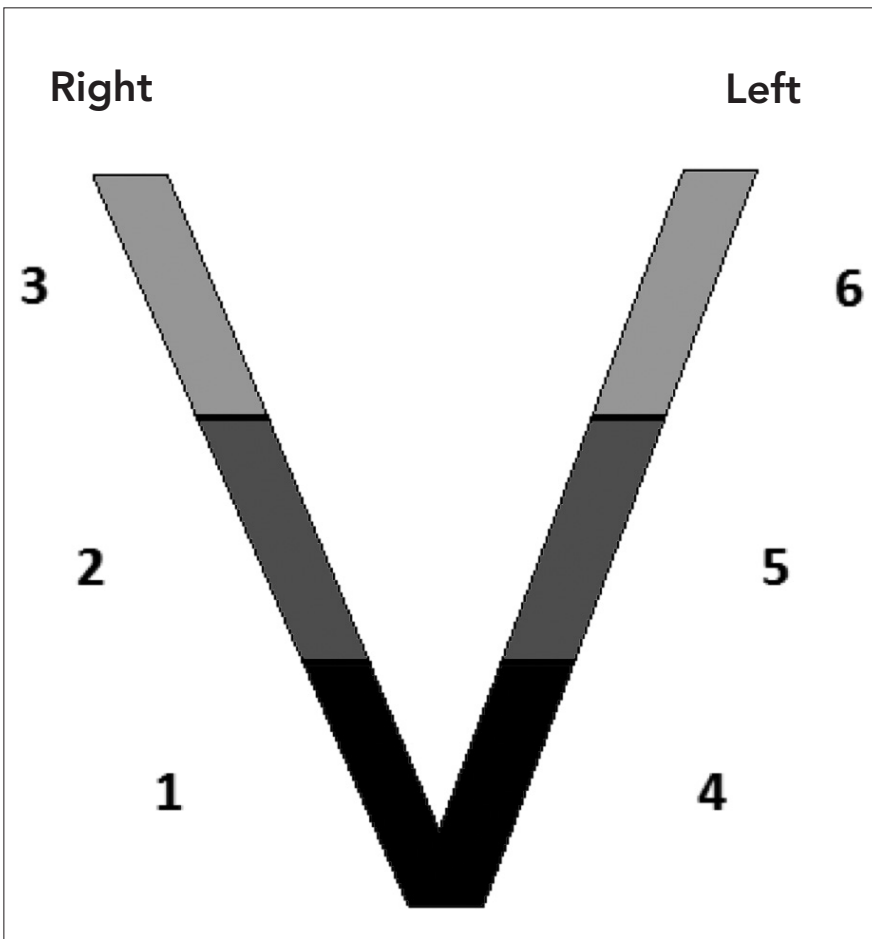

Figure 1. Lesion Location

significant $(p>0.05)$ in the patients with and without recurrence. The leukoplakia recurrence rate was significantly higher when compared to irregularity $(p<0.05)$ (Table 2$)$. When the histopathological results were examined according to the age distribution of the patients, the mean age was found to be higher in cases with micro-invasive and invasive SCC; it was observed that as the severity of dysplasia increased, the average age increased.

\section{DISCUSSION}

In 1930 for the first time, Jackson et al. (4) showed in a study the development of SCC on the surface of laryngeal keratosis and proposed that laryngeal keratosis was a pre-neoplastic lesion. Gale et al. (5) found in the literature that the rate of conversion to carcinoma varied between $0 \%$ and $57 \%$, and heavy dysplasia had a higher conversion rate. Weller et al. (6) found in the meta-analysis (9 studies, 940 patients) in 2010 the malignant transformation rate of laryngeal leukoplakia at $14 \%$, and the mean duration of carcinoma development 5.8 years.

It was seen that as the degree of dysplasia increased, the rate of malignant transformation also increased (severe/CIS, 30.4\%; mild to moderate, 10.6\%) (1). Isenberg et al. (7), in their review, reported that 256 (8.2\%) malignant transformations were observed in a 1-300 month follow-up of 3107 biopsies. They found that the severity of dysplasia in the first biopsy was proportional to the development of carcinoma.

In our study, the presence of dysplasia was found in $82 \%$ of the biopsies conducted. Isenberg et al. (7) in their review reported that $47.1 \%$ of the biopsies conducted in their own clinic and 
Table 1. General features

\begin{tabular}{|c|c|c|c|c|c|}
\hline & & Min. & Max. & \multicolumn{2}{|c|}{ Mean $\pm S D$ / n-\% } \\
\hline Age & & 30 & 86 & \multicolumn{2}{|c|}{$56.96 \pm 11.36$} \\
\hline \multirow[t]{2}{*}{ Gender } & Female & & & 10 & $10.3 \%$ \\
\hline & Male & & & 87 & $89.7 \%$ \\
\hline \multirow[t]{2}{*}{ Smoking } & No & & & 6 & $6.2 \%$ \\
\hline & Yes & & & 91 & $93.8 \%$ \\
\hline $\begin{array}{l}\text { First symptom duration } \\
\text { (month) }\end{array}$ & & 15 Days & 240 & \multicolumn{2}{|c|}{$18.5 \pm 32.5$} \\
\hline \multirow[t]{3}{*}{ Number of applications } & I & & & 60 & $61.9 \%$ \\
\hline & $\|$ & & & 24 & $24.7 \%$ \\
\hline & $\|I\| \leq$ & & & 13 & $13.4 \%$ \\
\hline \multirow[t]{2}{*}{ Examination } & Leukoplakia (homogenous) & & & 103 & $59.5 \%$ \\
\hline & Irregularity (non-homogenous) & & & 70 & $40.5 \%$ \\
\hline \multirow[t]{3}{*}{ Localization } & Right & & & 77 & $44.5 \%$ \\
\hline & Left & & & 87 & $50.3 \%$ \\
\hline & Bilateral & & & 12 & $6.9 \%$ \\
\hline \multirow[t]{3}{*}{ Localization } & Anterior & & & 146 & $84.4 \%$ \\
\hline & Middle & & & 107 & $61.8 \%$ \\
\hline & Posterior & & & 72 & $41.6 \%$ \\
\hline \multirow[t]{7}{*}{ Pathology } & Inflammatory change & & & 15 & $8.7 \%$ \\
\hline & Mild dysplasia & & & 76 & $43.9 \%$ \\
\hline & Moderate dysplasia & & & 14 & $8.1 \%$ \\
\hline & Severe dysplasia & & & 19 & $11.0 \%$ \\
\hline & Carcinoma in situ & & & 33 & $19.1 \%$ \\
\hline & Micro-invasive carcinoma & & & 6 & $3.5 \%$ \\
\hline & Invasive SCC & & & 10 & $5.8 \%$ \\
\hline \multirow[t]{2}{*}{ Reflux } & No & & & 82 & $84.5 \%$ \\
\hline & Yes & & & 15 & $15.5 \%$ \\
\hline
\end{tabular}

$48.2 \%$ in other studies revealed dysplasia. Ma et al. (8) stated that $72.5 \%$ of the biopsies revealed pre-cancerous lesion (mild, moderate, and severe dysplasia).

The most common pathological finding in our study was mild dysplasia (44\%). Carcinoma was diagnosed in $9 \%$ of the cases. In the study by Kizil et al. (9), pathology findings showed mild dysplasia to be the most common pathology seen in $25.8 \%$ of the patients, and $18.2 \%$ of the patients had carcinoma. Isenberg et al. (5) in his review of 2007 stated that 2188 biopsies showed no dysplasia in $53.6 \%$ of cases, $33.5 \%$ showed mildto-moderate dysplasia, and $15.2 \%$ showed severe dysplasia/ carcinoma in situ.
In terms of localization, in our study, it was observed that the anterior part of the vocal cords was involved more frequently (84\%). In 2012, Kizıl et al. (9) showed that the anterior and middle parts of the vocal cord were more involved, and the posterior involvement was less. Kalter et al. (10) in a study including 200 patients showed that the lesions with different degrees of dysplasia were mostly located in the anterior two-thirds, and only $11 \%$ of the patients had posterior one-third involvement.

In our study, it was found that leukoplakia, which had a clinically homogenous feature, had a higher recurrence rate than non-homogenous irregularity (46.6\%/23.1\%). On the other hand, the age distribution, sex ratio, first symptom duration, reflux rate, smoking rate, and localization did not increase the recurrence rate. 


\section{Table 2. Relapse values}

\begin{tabular}{|c|c|c|c|c|c|c|}
\hline & & \multicolumn{4}{|c|}{ Relapse } & \multirow[b]{3}{*}{$p$} \\
\hline & & \multirow{2}{*}{\multicolumn{2}{|c|}{$\begin{array}{c}\text { No } \\
\text { Mean } \pm S D / n-\%\end{array}$}} & \multicolumn{2}{|c|}{ Yes } & \\
\hline & & & & \multicolumn{2}{|c|}{ Mean $\pm S D / n-\%$} & \\
\hline Age & & \multicolumn{2}{|c|}{$58.1 \pm 11.4$} & 55.0 & \pm 11.3 & $0.200^{t}$ \\
\hline \multirow[t]{3}{*}{ Gender } & Female & 5 & 50.0 & 5 & 50.0 & \multirow[t]{2}{*}{$0.373^{2}$} \\
\hline & Male & 56 & 64.4 & 31 & 35.6 & \\
\hline & First symptom duration (month) & \multicolumn{2}{|c|}{$20.5 \pm 38.1$} & \multicolumn{2}{|c|}{$15.2 \pm 19.9$} & $0.615^{\mathrm{m}}$ \\
\hline \multirow[t]{2}{*}{ Examination } & Leukoplakia (homogenous) & 31 & 53.4 & 27 & 46.6 & \multirow[t]{2}{*}{$0.019 x^{2}$} \\
\hline & Irregularity (non-homogenous) & 30 & 76.9 & 9 & 23.1 & \\
\hline \multirow[t]{2}{*}{ Reflux } & No & 51 & 62.2 & 31 & 37.8 & \multirow[t]{2}{*}{$0.742^{x^{2}}$} \\
\hline & Yes & 10 & 66.7 & 5 & 33.3 & \\
\hline \multirow[t]{2}{*}{ Smoking } & No & 4 & 66.7 & 2 & 33.3 & \multirow[t]{2}{*}{$0.843^{x^{2}}$} \\
\hline & Yes & 57 & 62.6 & 34 & 37.4 & \\
\hline \multirow[t]{3}{*}{ Localization } & Right & 25 & 56.8 & 19 & 43.2 & \multirow[t]{3}{*}{$0.277 x^{2}$} \\
\hline & Left & 32 & 71.1 & 13 & 28.9 & \\
\hline & Bilateral & 4 & 50.0 & 4 & 50.0 & \\
\hline \multirow[t]{3}{*}{ Localization } & Anterior & 50 & 61.0 & 32 & 39.0 & \\
\hline & Middle & 43 & 65.2 & 23 & 34.8 & \\
\hline & Posterior & 27 & 64.3 & 15 & 35.7 & \\
\hline \multirow[t]{7}{*}{ Pathology } & Inflammatory change & 5 & 62.5 & 3 & 37.5 & \\
\hline & Mild dysplasia & 30 & 63.8 & 17 & 36.2 & \\
\hline & Moderate dysplasia & 3 & 60.0 & 2 & 40.0 & \\
\hline & Severe dysplasia & 9 & 100.0 & 0 & 0.0 & \\
\hline & Carcinoma in situ & 5 & 29.4 & 12 & 70.6 & \\
\hline & Micro-invasive carcinoma & 2 & 50.0 & 2 & 50.0 & \\
\hline & Invasive SCC & 7 & 100.0 & 0 & 0.0 & \\
\hline
\end{tabular}

\section{CONCLUSION}

In laryngeal leukoplakia, histopathological examination with biopsy is important for the evaluation of epithelial dysplasia and the grade. Factors such as the presence and the severity of dysplasia with regard to histopathology and smoking increase the risk of malignancy. It has been found that leukoplakia, which has a clinically homogenous feature, has a higher recurrence rate than non-homogenous irregularity. On the other hand, the age distribution, sex ratio, first symptom duration, reflux rate, smoking rate, and localization did not increase the recurrence rate.

Ethics Committee Approval: Ethics committee approval was received for this study from the Ethics Committee of Health Sciences University Şişli Hamidiye Etfal Training and Reseacrh Hospital. (Approval No.: 505; Approval Date: 22.10.2013).
Informed Consent: Informed consent was not taken from patients due to the retrospective nature of the study.

Peer-review: Externally peer-reviewed.

Author Contributions: Concept - F.T., M.E.A.; Design - I.U.; Supervision - I.U., F.T.; Resources - B.U., F.T.; Materials - F.T., M.E.A.; Data Collection and/or Processing - I.U., F.T.; Analysis and/or Interpretation - E.O., F.T.; Literature Search - B.U.; Writing Manuscript - F.T., B.U.; Critical Review - B.U.

Conflict of Interest: The authors have no conflict of interest to declare.

Financial Disclosure: The authors declared that this study has received no financial support.

\section{REFERENCES}

1. Kramer IR, Lucas RB, Pindborg JJ, Sobin LH. Collaborating Center for Oral Precancerous Lesions. Definition of leukoplakia and related 
lesions: an aid to studies on oral precancer. Oral Surg Oral Med Oral Pathol 1987; 46: 518-39.

2. Bailey BT: Early glottic carcinoma. In: Bailey BT, editör. Head and Neck Surgery-Otolaryngology. 2nd ed. Philadelphia: Lippincott-Raven; 1998.p.1703-24.

3. Hoffman HT, McCulloch TM: Manegement of early glottic cancer. In: Cammings CW, Fredrickson JM, Harker LA, Krause CJ, Richardson MA, Schuller DE, editors. Otolaryngology-Head and Neck Surgery 3rd ed. Missouri; Mosby; 1998.p.2187-205.

4. Jackson C, Colledge L, Thomson S. Discussion on precancerous conditions of the larynx. Proc R Soc Med 1930; 24: 301-8.

5. Gale N, Michaels L, Luzar B, Poljak M, Zidar N, Fischinger J, et al. Current review on squamous intraepithelial lesions of the larynx. Histopathology 2009; 54: 639-56. [CrossRef]

6. Weller MD, Nankivell PC, McConkey C, Paleri V, Mehanna HM. The risk and interval to malignancy of patients with laryngeal dysplasia; a systematic review of case series and meta-analysis. Clin Otolaryngol 2010; 35: 364-72. [CrossRef]

7. Isenberg, Jason S, MD, PhD;Crozier, Daniel L, MD;Dailey, Seth H, MD Institutional and Comprehensive Review of Laryngeal Leukoplakia. Ann Otol Rhinol Laryngol 2008; 117: 74-9. [CrossRef]

8. Ma LJ, Wang J, Xiao Y, Ye JY, Xu W, Yang OW. Clinical classification and treatment of leukokeratosis of the vocal Cords. Chin Med J (Engl) 2013; 126: 3523-7.

9. Kizil Y, Aydın U, Yilmaz M, Ekinci Ö, Guzeldir OT, Savas VA, et al. Vocal Cord Leukoplakia: Characteristics and Patological Significance. Int J Phonosurg Laryngol 2012; 2: 9-13. [CrossRef]

10. Kalter PO, Lubsen H, Delemarre JF, Snow GB. Squamous cell hypcrplasia of the larynx (a clinical follow-up study). J Laryngol Otol 1987; 101: 579-88. 